\title{
Study on Infants of Diabetic Mothers in Neonatal Intensive Care Unit of Misurata Teaching Hospital -Libya/2015
}

\author{
Salima A, Moktar A, Hanan J and Bashir A* \\ ${ }^{1}$ Department of Pediatric and Neonatology, Misurata University, Libya
}

*Corresponding author: Bashir Ashur, Department of Pediatric and Neonatology, Faculty of Medicine, Misurata University, Misurata Teaching Hospital, Misurata, Libya

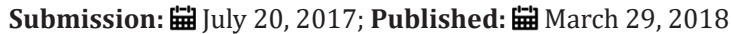

\begin{abstract}
Background: Infants born to mothers with diabetes have been at significantly greater risk for perinatal morbidity and mortality. Practitioners have sought to improve the outcome of diabetic pregnancies through proper maternal glycemic control.

Objective: To estimate the proportion of neonatal complications and death among infants of diabetic mothers. Methods: This observational cross sectional study was conducted in Misurata teaching hospital between January and December 2015. We retrospectively analyzed the NICU and Neonatology record files of 90 infants of diabetic mothers (IDMs) during the study period. Data on sex, gestational age, birth weight, maternal age, parity, mode of delivery, Apgar score, neonatal complications and investigations were collected.
\end{abstract}

Results: Out of 90 IDMs, 20(22.2\%) were delivered preterm, 40(44.4 \%) had birth wt more than $4 \mathrm{Kg}$, 12(13.3 \%) had Apgar score less than 7 at $1 \mathrm{~min}, 35(38.9 \%)$ had blood sugar less than 45 at 1 hour, 47(52.2\%) needed IVF for control of blood sugar. 71(78.9\%) were delivered by C/S $31(34.5 \%)$ of which were urgent and 60(66.7\%). 20(22.2\%) developed hypoglycemia, $9(10 \%)$ developed hypocalcaemia and 7(7.8\%) developed hyper bilirubinemia. RDS developed in 23(25.5\%), Neonatal sepsis in 5(5.6\%), TTN in 8(8.8\%), Birth asphyxia in 1(1.1\%), congenital anomalies in 24(26.6\%), CHD in $19(21.1 \%)$ and mortality was $1(1.1 \%)$.

Conclusion: Macrosomia, preterm birth, congenital anomalies, CHD, RDS, TTN, hypoglycemia, hypocalcaemia and hyperbillirubinaemia are significant complications among IDMs. Screening of all pregnant women for diabetes, good glycemic control and opening of gestational diabetes clinic on a national scale is highly recommended.

Keywords: Infant; Diabetes mellitus; Mother; Morbidity; Mortality

\section{Introduction}

Diabetes mellitus (DM) is a global health problem affecting young adults and women in their reproductive age. The World Health Organization (WHO) has predicted that between 1995 and 2025 , there will be a $35 \%$ increase in the worldwide prevalence of diabetes [1].

Diabetes mellitus is the commonest endocrine disorder during pregnancy 6 and abnormal maternal glucose regulation occurs in $3-10 \%$ of pregnancies and the prevalence is increasing. Diabetes has long been associated with maternal and perinatal morbidity and mortality [2].

Diabetes in Pregnant women could be either pregestational or gestational. Gestational diabetes accounts for about $80 \%$ of cases and could represent a predisposition to an extreme manifestation of metabolic changes during pregnancy [3].

Infant of diabetic mothers have a $47 \%$ risk of significant hypoglycaemia, $22 \%$ risk of hypocalcaemia, $19 \%$ risk of hyperbilirubinemia, 34\% risk of polycythaemia, 6-9\% incidence of major congenital anomalies, $4 \%$ risk of respiratory distress syndrome, $28 \%$ risk of macrosomia [2-4]. These risks can be minimized by optimal glycaemic control, both prior to and throughout the pregnancy [5].

Macrosomia (birth weight $>4000 \mathrm{~g}$ ) may be associated with increased incidence of primary caesarean section or obstetric trauma such as fractured clavicle, Erb's palsy or phrenic nerve palsy due to shoulder dystocia [2]. Among the various metabolic errors these infants suffer, hypoglycaemia is the commonest and most dangerous. Neonatal hypocalcaemia may be due to hypoparathyroidism, abnormal vitamin D metabolism and hyperphosphataemia [6].

Studies have shown higher mortality amongst infants of diabetic mothers (IDM) compared to controls. The neonatal mortality rate is over five times that of infants of non-diabetic mothers [5]. Although most of the morbidity and mortality data 
for the IDM improved with time, congenital anomalies remain a significant unresolved problem, three to four times, that is found in a general neonatal population [5]. In view of the high morbidity and mortality associated with this condition, this study was conducted in Misurata Teaching Hospital with the aim to identify the neonatal complications among infants of diabetic mothers.

\section{Methods}

\section{Study setting}

This study was conducted as a descriptive cross sectional study at the neonatal intensive care unit of Misurata teaching hospital in Libya, based on hospital files records. We retrospectively analyzed the hospital records over a period of one year between January 2015 to December 2015.

\section{Study subjects}

Our study included 90 IDMs born during the study period were admitted to the neonatal care unit after delivery. All of them were born to mothers with either gestational or pregestational (type 1 or type 2) diabetes.

\section{Ethical issue}

Approval was granted from the hospital administration prior to the collection of data from the hospital records.

\section{Data collection}

The collected data includes

A) Maternal characteristics: (i) age, (ii) parity, (iii) mode of delivery, (iv) Type of diabetes, (v) mode of control.

B) Neonatal characteristics: (i) sex, (ii) gestational age, (iii) birth weight and those who weighed $4 \mathrm{~kg}$ or more were classified as macrosomic.

C) Apgar score, results of physical examination that was performed.

D) Laboratory investigations done: blood sugar, calcium and bilirubin levels.

A diagnosis of hypoglycaemia and hypocalcaemia was recorded for neonates with serum glucose levels $<35 \mathrm{mg} / \mathrm{dL}$, and serum calcium below $7 \mathrm{mg} / \mathrm{dl}$ respectively. A diagnosis of hyperbillirubinaemia was recorded for neonates with total serum bilirubin above $5 \mathrm{mg} / \mathrm{dl}$.

\section{Statistical analysis}

Date was analyzed by SPSS software version 18 and the results was summarized, presented and displayed as frequencies and percentage in suitable tables. Statistical analysis of qualitative data was performed using Chi-square test, while fisher exact test was used if there is an expected value in a cell $<5$. Results were accepted as significant when $(\mathrm{p}<0.05)$.

\section{Results}

There is no statistical significant difference in infants of diabetic mothers regarding to sex distribution (Table 1).
Table 1: Distribution of infants of diabetic mothers according to gender.

\begin{tabular}{|c|c|c|}
\hline \multirow{2}{*}{ Gender } & \multicolumn{2}{|c|}{ Total Number of Studied Infants (90) } \\
\cline { 2 - 3 } & N. & \% \\
\hline Boy & 45 & 50 \\
\hline Girl & 45 & 50 \\
\hline Total & 90 & 100 \\
\hline
\end{tabular}

Majority of infants of diabetic mothers are born to mothers aged $35-40$ years $(41.1 \%)$ and those aged $30-35$ years $(25.6 \%)$ and that is highly statistically significant (Table 2 ).

Table 2: Distribution of infants of diabetic mothers according to maternal age.

\begin{tabular}{|c|c|c|}
\hline \multirow{2}{*}{ Maternal Age } & \multicolumn{2}{|c|}{ Total Number of Studied Infants (90) } \\
\cline { 2 - 3 } & N. & $\%$ \\
\hline$\leq 20$ & 2 & 2.2 \\
\hline-25 & 2 & 2.2 \\
\hline-30 & 14 & 15.6 \\
\hline-35 & 23 & 25.6 \\
\hline-40 & 37 & 41.1 \\
\hline-45 & 11 & 12.2 \\
\hline$>45$ & 1 & 1.1 \\
\hline Total & 90 & 100 \\
\hline
\end{tabular}

Most of infants of diabetic mothers (90\%) are borne to multi-gravid mothers, $58.9 \%$ of mothers having less than 5 births, while $31.1 \%$ having more than 5 births, and that is highly statistically significant (Table 3).

Table 3: Distribution of infants of diabetic mothers according to mothers' parity.

\begin{tabular}{|c|c|c|}
\hline \multirow{2}{*}{ Mother's Parity } & \multicolumn{2}{|c|}{ Total Number of Studied Infants (90) } \\
\cline { 2 - 3 } & N. & $\%$ \\
\hline PG & 5 & 5.6 \\
\hline G1 & 4 & 4.4 \\
\hline-5 & 53 & 58.9 \\
\hline$>5$ & 28 & 31.1 \\
\hline Total & 90 & 100 \\
\hline
\end{tabular}

$\begin{array}{lll}\text { Chi Square }=34.3 & \mathrm{p}<0.001 & \text { (Highly Significant) }\end{array}$ 
About $78.9 \%$ of infants of diabetic mothers are delivered by CS. $44.4 \%$ of them by Elective CS and $34.5 \%$ by Urgent CS. While, only $21.1 \%$ were delivered by NVD (Table 4).

Table 4: Distribution of infants of diabetic mothers according to mode of delivery.

\begin{tabular}{|c|c|c|}
\hline \multirow{2}{*}{ Mode of Delivery } & \multicolumn{2}{|c|}{ Total Number of Studied Infants (90) } \\
\cline { 2 - 3 } & $\mathbf{N .}$ & \% \\
\hline N.V.D & 19 & 21.1 \\
\hline Elective C $\backslash S$ & 40 & 44.4 \\
\hline Urgent C $\backslash S$ & 31 & 34.5 \\
\hline Total & 90 & 100 \\
\hline
\end{tabular}

Chi Square $=16.4 \quad \mathrm{p}<0.001 \quad$ (Highly Significant)

Regarding gestational age, the majority of infants of diabetic mothers are borne full-term 37-40 Wks (71.1\%). While, preterm and post-term babies represents $(22.2 \%$ and $6.7 \%)$ respectively and that is highly statistically significant (Table 5).

Table 5: Distribution of infants of diabetic mothers according to gestational age.

\begin{tabular}{|c|c|c|}
\hline \multirow{2}{*}{ Gestational Age } & \multicolumn{2}{|c|}{ Total Number of Studied Infants (90) } \\
\cline { 2 - 3 } & $\mathbf{N .}$ & \% \\
\hline $\begin{array}{c}\text { Preterm birth <37 } \\
\text { Wks }\end{array}$ & 20 & 22.2 \\
\hline $\begin{array}{c}\text { Full-term birth 37- } \\
\text { 40 Wks }\end{array}$ & 64 & 71.1 \\
\hline $\begin{array}{c}\text { Post-term birth > } \\
40 \text { Wks } \\
\text { Total }\end{array}$ & 6 & 6.7 \\
\hline
\end{tabular}

Chi Square $=30.3 \quad \mathrm{p}<0.001 \quad$ (Highly Significant)

About $45.6 \%$ of infants of diabetic mothers are borne having normal birth weight. Macrosomia is a major problem among these infants representing $44.4 \%$, and that is highly statistically significant. While, LBW accounts are only for $10 \%$ (Table 6).

Table 6: Distribution of infants of diabetic mothers according to birth weight.

\begin{tabular}{|c|c|c|}
\hline \multirow{2}{*}{ Birth Weight } & \multicolumn{2}{|c|}{ Total Number of Studied Infants (90) } \\
\cline { 2 - 3 } & $\mathbf{N .}$ & $\mathbf{\%}$ \\
\hline $\begin{array}{c}\text { VLBW }(1.001-\leq 1.5 \\
\text { Kg) }\end{array}$ & 1 & 1.1 \\
\hline LBW $(1.501-\leq 2.5 \mathrm{Kg})$ & 8 & 8.9 \\
\hline $\begin{array}{c}\text { Normal birth weight } \\
(2.5-\leq 4 \mathrm{Kg})\end{array}$ & 41 & 45.6 \\
\hline $\begin{array}{c}\text { Macrosomia }(\geq 4 \mathrm{Kg}) \\
\text { Total }\end{array}$ & 40 & 44.4 \\
\hline Chi Square $=14.4$ & $\mathrm{p}<0.001 \quad$ (Highly Significant) \\
\hline
\end{tabular}

About $86.7 \%$ of the studied infants have APGAR score $\geq 7$ and only $13.3 \%$ of them have APGAR score $<7$ (Table 7).
Table 7: Distribution of infants of diabetic mothers according to APGAR score.

\begin{tabular}{|c|c|c|}
\hline \multirow{2}{*}{ APGAR Score } & \multicolumn{2}{|c|}{ Total Number of Studied Infants (90) } \\
\cline { 2 - 3 } & $\mathbf{N}$ & $\%$ \\
\hline$<7$ & 12 & 13.3 \\
\hline$\geq 7$ & 78 & 86.7 \\
\hline Total & 90 & 100 \\
\hline Chi Square = 20.8 & $\mathrm{p}<0.001$ & (Highly Significant) \\
\hline
\end{tabular}

Only $22.2 \%$ of the studied infants showed hypoglycemia and have first blood sugar level $<35$ while, most of them have blood sugar level $\geq 45$ (Table 8).

Table 8: Distribution of infants of diabetic mothers according to first blood sugar level.

\begin{tabular}{|c|c|c|}
\hline \multirow{2}{*}{$\begin{array}{c}\text { First Blood } \\
\text { Sugar Level }\end{array}$} & \multicolumn{2}{|c|}{ Total Number of Studied Infants (90) } \\
\cline { 2 - 3 } & $\mathbf{N .}$ & $\%$ \\
\hline$<35$ & 20 & 22.2 \\
\hline $35-44$ & 15 & 16.7 \\
\hline$\geq 45$ & 55 & 61.1 \\
\hline Total & 90 & 100 \\
\hline Chi Square $=14.3$ & $\mathrm{p}<0.001 \quad$ (Highly Significant)
\end{tabular}

Regarding the need to use intra-venous fluids to control cases, IVF was used in $52.2 \%$ of the studied cases with no statistical significant difference (Table 9).

Table 9: Distribution of infants of diabetic mothers according to the need to use IVF for control.

\begin{tabular}{|c|c|c|}
\hline \multirow{2}{*}{ Need to Use IVF } & \multicolumn{2}{|c|}{ Total Number of Studied Infants (90) } \\
\cline { 2 - 3 } & N. & $\%$ \\
\hline IVF used & 47 & 52.2 \\
\hline IVF not needed & 43 & 47.8 \\
\hline Total & 90 & 100 \\
\hline Chi Square = 0.9 & \multicolumn{2}{|c|}{$\mathrm{p}=0.76$ (Non-Significant) }
\end{tabular}

The main complications and associated co-morbidities among infants of diabetic mothers are macrosomia (44.4\%), congenital anomalies (26.7), RDS (25.5\%), preterm birth (22.2\%), hypoglycemia (22.2\%) and CHD (21.1\%), and these complications are statistically significant. Also, hypocalcaemia and hyperbillirubinaemia are present in $(10 \%$ and $7.8 \%)$ respectively. While, only one case died (1.1\%) (Table 10). 
Table 10: Neonatal complications and associated comorbidities among infants of diabetic mothers.

\begin{tabular}{|c|c|c|}
\hline \multirow{2}{*}{$\begin{array}{c}\text { Neonatal Complications } \\
\text { and Associated Co- } \\
\text { morbidities }\end{array}$} & $\begin{array}{c}\text { Total Number of Studied Infants } \\
\text { (90) }\end{array}$ \\
\cline { 2 - 3 } & N. & \% \\
\hline Preterm birth & 20 & 22.2 \\
\hline Post-term birth & 6 & 6.7 \\
\hline Low birth weight & 1 & 1.1 \\
\hline Very low birth weight & 8 & 8.9 \\
\hline Macrosomia & 40 & 44.4 \\
\hline RDS & 23 & 25.5 \\
\hline Sepsis & 5 & 5.6 \\
\hline TTN & 8 & 8.9 \\
\hline Birth asphyxia & 1 & 1.1 \\
\hline
\end{tabular}

\begin{tabular}{|c|c|c|}
\hline Congenital anomalies & 24 & 26.7 \\
\hline CHD & 19 & 21.1 \\
\hline Hypoglycaemia & 20 & 22.2 \\
\hline Hypocalcaemia & 9 & 10 \\
\hline Hyperbillirubinaemia & 7 & 7.8 \\
\hline Neonatal death & 1 & 1.1 \\
\hline Total & 90 & 100 \\
\hline Chi Square $=49.3$ & $\mathrm{p}<0.001 \quad$ (Highly Significant)
\end{tabular}

Chronic diabetes mellitus was founded among 37.8\% of infants' mothers, while $62.2 \%$ was diagnosed as gestational diabetes. There is a significant higher use of insulin in treatment of chronic DM and significant higher dependence on diet control among those with gestational diabetes (Table 11).

Table 11: Distribution of IDMs according to the type of DM and the used treatment.

\begin{tabular}{|c|c|c|c|c|c|c|c|}
\hline \multirow[t]{2}{*}{ Treatment } & \multicolumn{2}{|c|}{$\begin{array}{l}\text { Chronic DM } \\
34(37.8 \%)\end{array}$} & \multicolumn{2}{|c|}{$\begin{array}{c}\text { Gestational Diabetes } \\
56(62.2 \%)\end{array}$} & \multicolumn{2}{|c|}{$\begin{array}{l}\text { Total Number of Studied Infants N. } \\
\qquad(90)\end{array}$} & \multirow[t]{2}{*}{ P. Value } \\
\hline & N. & $\%$ & N. & $\%$ & N. & $\%$ & \\
\hline Insulin & 31 & 91.2 & 20 & 35.7 & 51 & 56.7 & $<0.001^{*}$ \\
\hline OHG & 2 & 5.9 & 6 & 10.7 & 8 & 8.9 & 0.43 \\
\hline Diet control & 1 & 2.9 & 30 & 53.6 & 31 & 34.4 & $<0.001^{*}$ \\
\hline
\end{tabular}

\section{Discussion}

Diabetes is a prevalent medical problem during pregnancy and abnormal maternal glucose regulation occurs in $3-10 \%$ of pregnancies and the prevalence is increasing. Diabetes in pregnancy is associated with an increased risk of some adverse pregnancy outcome in both the mother and the fetus [2].

In this study, most of mothers of the studied infants belong to $35-40$ years $(41.1 \%)$ and $30-35$ years $(25.6 \%)$ age group respectively. This nearly approaches findings of Kheir et al. [5] in his study conducted in Khartoum, showed that most of diabetic mothers who gave birth at Soba university hospital were of 30-39 years age group.5 Increasing maternal age was associated with higher frequency of GDM, which was in accordance with other studies [7-9]. This emphasis upon screening blood glucose levels of women over 30 years [10].

Our study revealed a highly significant association between parity and maternal gestational diabetes (p-value < 0.001); 90\% of mothers who had gestational diabetes in our study were multigravid. Increasing parity was well demonstrated as an associated risk factor for GDM. That is in agreement with Qadir et al. [10] in their study in Pakistan, who find multi-gravid were $76 \%$ and Randhawa reported $80 \%$ of patients with GDM were multi-parous [9]. While, Kheir et al. [5] found that $59.7 \%$ of mothers who had gestational diabetes were multiparous and $40.7 \%$ were primiparous.

Based on the observations of the present study, $71.1 \%$ of the IDMs were full-term with gestational age (37-40 Wks), while preterm ( $<37 \mathrm{Wks}$ ) and post-term ( $>40 \mathrm{Wks}$ ) represented only $22.2 \%$ and $6.7 \%$ respectively. It is higher than what observed in the study of Mahmood and Kayes, conducted in Bangladesh, as only $7.6 \%$ was preterm delivery [2]. While, Ranade et al. [11] reported a higher rate, about $36 \%$ of the IDMs were preterm. IDMs may need to be delivered prematurely due to maternal or fetal problems. Overall, $26 \%$ of the diabetic women deliver before 37 weeks gestation, compared with $10 \%$ in general population [2].

In this study, majority of the mothers (78.9\%) delivered by caesarian section compared to $21.1 \%$ normal delivery, most of them delivered by elective caesarian section (44.4\%). Our findings were similar to the findings in a Sri-Lankan study [12] where elective C/S rates were much higher than emergencies and Kheir et al. [5] where $84 \%$ delivered by CS, $60 \%$ of them delivered by elective-CS. Which is in contrast to the study done in Nigeria by Opara et al. [3], who found that most of the caesarian sections were emergency. The high rate of operative deliveries, similar to the other study is related to high incidence of macrosomia in IDMs [6].

While, our results disagrees with the findings of Woon et al [13] who reported $41.8 \%$ caesarean section rate, the study of Qadir et al. [10] where the rate of CS was $58 \%$ and the study done in Sir Ganga Ram Hospital, Lahore [14].

Chronic diabetes mellitus was founded among 37.8\% of infants' mothers, while $62.2 \%$ was diagnosed as gestational diabetes. There is a significant higher use of insulin in treatment of chronic DM and significant higher dependence on diet control among those with gestational diabetes. 
In our study, neonatal complications among infant of diabetic mothers are macrosomia (44.4\%), congenital anomalies (26.7), RDS (25.5\%), preterm birth (22.2\%), hypoglycemia (22.2\%), CHD (21.1\%), hypocalcaemia (10\%), TTN (8.9\%) and hyperbillirubinaemia (7.8\%) and these complications are statistically significant. The most common neonatal complications observed in this study were macrosomia which occurred in (44.4\%). This higher incidence of macrosomia is similar to the findings (48\%) of Qadir et al. [10] and also comparable to the study from developing world (46.6\%) [15]. While, this incidence is higher than founded in many other studies as Kheir et al. [5] where macrosomia occurred in (28\%) and that in another Nigerian study [16].

Macrosomia is associated with increased risk for traumatic birth injury, obesity, and diabetes in later life. 3 Foetal hyperinsulinism as a cause for macrosomia was proposed more than 25years ago.10 most authors agree that macrosomia is in part related to maternal glucose control $[3,5,10]$. In the present study $22.2 \%$ infants showed hypoglycaemia which was similar to the study by Mahmood and Kayes,2 where 23\% infants having hypoglycaemia. Ranade et al. [11], Hossain et al. [17] and Mountain [18] reported the incidence to be $50 \%, 52.8 \%$ and $55.2 \%$ respectively. While, these incidence was higher than that in the study of Qadir et al [10] and that of Mannan et al. [14] as only 8\% neonates showed hypoglycaemia. Good maternal glycaemic control during pregnancy and delivery decreases the risk of neonatal hypoglycaemia. So, neonatal hypoglycaemia has been identified as a marker of poor glycaemic control in the mothers [10].

In our study, $10 \%$ of the IDMs developed hypocalcaemia. It is probably due to functional hypoparathyroidism [12]. It has also been documented as a problem of IDMs by other authors. Marchant et al. [19] Opara et al. [3], Ahmed et al. [6], Ranade et al. [11] and Mountain [18] reported the incidence of hypocalcaemia to be $60 \%$, $23.4 \%, 22.8 \% 14 \%$, and $25-50 \%$ respectively.

Neonatal jaundice was noted less frequent in our IDMs (7.8\%), this is in contrast to the finding of many other studies where incidence of neonatal jaundice was much higher $[3,5,6,10]$. Opara et al. [3] had found that $63.8 \%$ of the IDMs had hyperbillirubinaemia. Hyperbilirubinemia is a recognized problem of IDMs, and has show to occur with increased frequency in macrosomic IDMs [5].

In this study, there were obvious congenital malformations and CHD as they were reported in $26.7 \%$ and $21.1 \%$ of IDMs respectively. This is almost similar to Woon et al. [13] in their study who found that occurred in $15.5 \%$ infants. While, this rate was just $2 \%, 3.8 \%, 4 \%$ and $5.7 \%$ in other studies $[2,10,14,20]$. This high incidence of congenital malformations indicates poor glycaemic control of diabetic mothers in our country.

In the study undertaken, RDS was founded in $25.5 \%$ of IDMs. That is similar to that reported by Ahmed et al in India (35\%) [6]. Also, studies done outside Africa recorded respiratory distress syndrome as the commonest cause of respiratory distress amongst IDMs $[3,12]$. While, this is higher than the findings of many other studies, where it was around $2 \%, 3.8 \%$ and $5.5 \%$ [2,5,10]. Also, this high incidence of RDS indicates poor glycaemic control of diabetic mothers in our country.

Transient tacypnoea of newborn (TTN) was common cause of respiratory distress among babies in this study (8.9\%). This is supported by findings of aome studies $[3,6]$. That was expected because most of them were also macrosomic and delivered by caesarian section, which on its own is a known risk factor.

In this study, perinatal asphyxia occurred in only $1.1 \%$ of IDMs. This is extremely lower than that founded in many other studies in which it exceeded $15 \%[2,3,6]$. About $86.7 \%$ of the studied infants have APGAR score $\geq 7$ and only $13.3 \%$ of them have APGAR score $<7$. IVF was used in $52.2 \%$ of the studied cases for control. This is a pointer to the need for screening of all pregnant women for diabetes and active management their infants of diabetic mothers irrespective of type of maternal diabetes.

\section{Conclusion}

The present study revealed a high incidence of complications among IDMs including macrosomia, preterm birth, congenital anomalies, CHD, RDS, TTN, hypoglycemia, hypocalcaemia and hyperbillirubinaemia but absence of obvious neonatal mortality. They were more likely to be delivered by caesarian sections. Screening of all pregnant women for diabetes is very important with good glycemic control and active management of their infants to have a satisfactory outcome in IDMs. Opening of gestational diabetes clinic with standard protocols for prevention and treatment of diabetes in pregnancy on a national scale is highly recommended.

\section{References}

1. Wild S, Roglic G, Green A, Sicree R, King H (2004) Global prevalence of diabetes: estimates for the year 2000 and projections for 2030. Diabetes Care 27: 1047-1053.

2. Mahmood CB, Kayes MI (2008) Problems and Immediate Outcome of Infants of Diabetic Mothers. Journal of Bangladesh College of Physicians and Surgeons. 26(2): 67-72.

3. Opara PI, Jaja T, Onubogu UC (2010) Morbidity and mortality amongst infants of diabetic mothers admitted into a special care baby unit in Port Harcourt, Nigeria. Ital J Pediatr 36(1): 77

4. Edward S Ogata (2010) Problems of the Infant of the Diabetic Mother. NeoReviews 11(11): 627-631.

5. Kheir AE, Berair R, Gulfan IG, Karrar MZ, Mohammed ZA (2012) Morbidity and mortality amongst infants of diabetic mothers admitted into Soba university hospital, Khartoum, Sudan. Sudan J Paediatr 12(1): 49-55.

6. Ahmed S, Rashid I, Shahzad N, Jan M (2015) Morbidity and Mortality amongst Infants of Diabetic Mothers (IDM) Admitted Into Neonatology Unit of G. B. Pant Children Hospital Srinagar. Journal of Dental and Medical Sciences 14(3): 9-13.

7. Khan A, Jaffarey SN (1997) Screening for gestational diabetes. Medical Channel 3: 8-12

8. Negrato CA, Jovanovic L, Rafacho A, Tambascia MA, Geloneze B, et al. (2009) Association between different levels of dysglycemia and metabolic syndrome in pregnancy. Diabetol Metab Syndr 1(1): 3. 
9. Randhawa MS, Moin S, Shoaib F (2003) Diabetes mellitus during pregnancy: a study of fifty cases. Pak J Med Sci 19(4): 277-282.

10. Qadir SY, Yasmin T, Fatima I (2011) Maternal and foetal outcome in gestational diabetes. J Ayub Med Coll Abbottabad 24(3-4): 17-20.

11. Ranade AY, Marchant RH, Bajaj RT, Joshi NC (1989) Infants of diabetic mother: an analysis of 50 cases. Indian Pediatr 26: 366-370.

12. Senanayake MP, Gunawardene MKS (2000) Neonatal morbidity following control of maternal diabetes mellitus with human insulin. Sri Lanka Journal of Child Health 29: 11-14.

13. Woon KY, Lim LS, Tan KL, Ng C, Yeo PBP, et al. (1985) The infants of a diabetic mother. J Singapore Paed Soc 27(1-2): 74-81.

14. Mannan J, Bhatti MT, Kamal K (1996) Outcome of pregnancies in diabetic mothers: A descriptive study. Pak J Obstet Gynaecol 9: 35-40.
15. Ferchiou M, Zhioua F, Hadhri N, Hafsia S, Mariah S (1994) Predictive factors of macrosomia in diabetic pregnancies. Rev Fr Gynecol Obstet 89(2): 73-76.

16. Ozumba BC, Obi SN, Olu JM (2004) Diabetes mellitus in pregnancy in an African population. Int S Gynaecol Obstet 84(2): 114-119.

17. Hossain MM, Kawser CA, Amin R, Talukder MQR (1994) Neonatal morbidity among infants born to diabetic mothers. Bangladesh J Child Health 15: 77-83.

18. Mountain KR (1991) The infant of the diabetic mother. Bailliere's Clin Obstet Gynaecol 5(2): 413-441.

19. Merchant RH, Dalvi R, Vidwans A (1990) Infant of the diabetic mother. Indian Paediatr 27: 373-379.

20. Perveen N, Saeed M (1996) Gestational diabetes and pregnancy outcome: Experience at Shaikh Zayed Hospital. Mother Child 34(3): 83-88.
Creative Commons Attribution 4.0 International License

For possible submissions Click Here
Submit Article

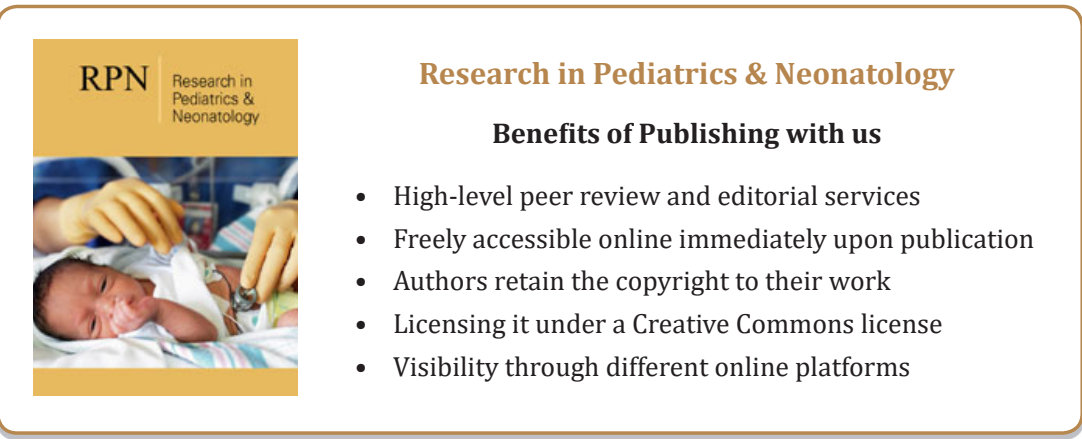

